\title{
İnflamatuvar barsak hastalıklarında epidemiyolojik özellikler ve hastalık farkındağı; İzmir örneği ile kesitsel bir çalışma
}

\author{
Epidemiological characteristics and awareness of inflammatory bowel diseases: a cross-sectional \\ study in Izmir
}

\author{
(DBerna Nilgün ÖZGÜRSOY URAN', (DElif SARITAŞ YÜKSEL², (DE Elif ÜNSAL AVDAL ${ }^{1}$, D Burcu ARKAN
}

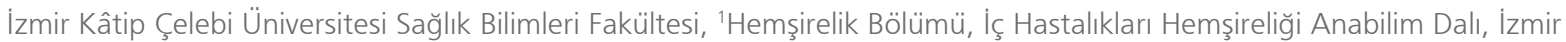
İzmir Kâtip Çelebi Üniversitesi Tıp Fakültesi, 'ªstroenteroloji Bilim Dalı, İzmir

Uludağ Üniversitesi Sağılı Bilimleri Fakültesi, ${ }^{3}$ Hemşirelik Bölümü, Psikiyatri Hemşireliği Anabilim Dalı, Bursa

\begin{abstract}
Giriş ve Amaç: Ülkemizde, inflamatuvar barsak hastalıkları olan bireylerin epidemiyolojik verilerine ve hastalık farkındalıklarına ilişkin yeterli sayıda çalışma bulunmamaktadır. Bu nedenle bu çalışmada inflamatuvar barsak hastalığı olgularının sosyodemografik ve epidemiyolojik verilerinin değerlendirilmesi ve hastalığa ilişkin farkındalıklarının araştırılması amaçlanmıştır. Gereç ve Yöntem: Bu çalışma kesitsel olarak planlanlandı ve İmir'de bir eğitim ve araştırma hastanesi gastroenteroloji polikliniğine Temmuz-Ekim 2015 tarihleri arasında inflamatuvar barsak hastalığı tanısı ile başvuran 104 hasta ile yürütüldü. Veriler, araştırmacılar tarafından oluşturulan 30 soruluk "Inflamatuvar Barsak Hastalıkları Tarama ve Farkındalık Anketi” ile toplanmıştır. Çalışmanın yapıldığı kurumdan ve hastalardan etik izinler alınmıştır. Çalışmada sınıflayıcı değişkenler için frekans ve yüzdeler, ayrıca sürekli değişkenler için ortalama, standart sapma ve median, oranların karşılaştırmalarında ise ki-kare testleri kullanılmıştır. Bulgular: Hastaların yaş ortalaması $42.5 \pm 13.9$ ve ortalama hastalık süresi $70.41 \pm 64.30$ aydır. Hastaların büyük çoğunluğu sigara kullanmamış veya bırakmıştır. Hastaların \%95.2'si tıbbi tanısını bilmekte ve \%60.6'sı ülseratif kolit olduğunu ifade etmektedir. Crohn hastası olanların \%56.8'i Crohn hastalığı tipini bilmektedir. Tüm hastaların \%57.8'i ise hastalığın tutulum yerini bilmekte; \%74'ü kullandıkları ilaçları bilmekte ya da kısmen bilmektedir. Hastaların Crohn hastalığı tipini bilme durumu ile cinsiyet arasında anlamlı bir ilişki saptanmış ve erkeklerin kadınlara oranla daha fazla oranla Crohn hastalığı tipini bildikleri görülmüştür. Öğrenim durumları ile Crohn hastalığı tipini bilme durumları arasındaki ilişkinin anlamlı olduğu, ortaokul ve üstü öğrenime sahip bireylerin hastalık tipini daha fazla bildiği saptanmıştır. Internetten bilgi alımı ile Crohn hastalığı tipini bilme durumları arasında da anlamIı bir ilişki olduğu, internetten bilgi alımı arttıkça Crohn hastalığı tipini bilme durumlarının da anlamlı olarak arttığı görülmüştür. Sonuç: Hastaların öz ve soy geçmişlerindeki veriler inflamatuvar barsak hastalıkları patogenezinde önemli rol oynamaktadır. Çalışma verilerimiz literatürün aksine hastalarımızın çoğunda ailesinde inflamatuvar barsak hastalığı öyküsü olmadığı ve herhangi başka bir hastalık ya da apendektomi öyküsü bulunmadığını; buna karşın literatürle uyumlu olarak inflamatuvar barsak hastalığı tanısı almadan önce bireylerin sigara kullandığını, tanı almadan önce dengesiz beslendiğini, eğitim seviyesi düşük olan bireylerde de inflamatuvar barsak hastalığı görüldüğünü ortaya koymuştur.
\end{abstract}

Anahtar kelimeler: Inflamatuvar barsak hastalıkları, epidemiyolojik özellikler, hastalık farkındalığı, ülseratif kolit, Crohn hastalığı

\footnotetext{
Illetişim: Berna Nilgün ÖZGÜRSOY URAN

İzmir Kâtip Çelebi Üniversitesi Sağlık Bilimleri Fakültesi,

ıç Hstalıkları Hemşireliği Anabilim Dalı, İzmir

E-mail: bernanilgun@gmail.com
}

Background and Aims: In Turkey, studies on epidemiological data and disease awareness in patients with inflammatory bowel diseases are insufficient. Therefore, the aim of this study was to assess the sociodemographic and epidemiological data of patients with inflammatory bowel diseases and investigate their awareness of this disease. Materials and Methods: This study was planned as a cross-sectional study and was conducted on 104 patients with inflammatory bowel diseases who were admitted to the gastroenterology outpatient clinic of a training and research hospital in Izmir and who were followed up after a diagnosis of inflammatory bowel diseases between July 2015 and October 2015. The data were collected via Inflammatory Bowel Diseases Screening and Awareness Questionnaires comprising 30 questions created by researchers. Ethical permissions were obtained from the institution and the patients. Frequency and percentages were used for classifying variables, and mean, standard deviation, and median were used for continuous variables. Chi-square test was used to compare ratios. Results: The mean age of the patients was $42.5 \pm 13.9$ years, and the mean duration of inflammatory bowel diseases was $70.41 \pm 64.30$ months. The majority of the patients did not smoke or had quitted smoking. Overall, $95.2 \%$ of the patients were aware of their medical diagnoses and $60.6 \%$ of them had ulcerative colitis. In addition, $56.8 \%$ of the patients with Crohn's disease were aware of their Crohn's disease types. Overall, $57.8 \%$ of all patients were aware of the location of the disease in their bodies; $74 \%$ of them were completely or partially aware of the drugs they used. There was a significant relationship between sex and awareness status about Crohn's disease types, and the male patients were more likely to be aware of their Crohn's disease type than the female patients. The relationship between educational status and awareness status about Crohn's disease type was significant, and the patients with middle and high school education were more aware of their disease type. There was a significant relationship between information retrieval from the Internet and awareness status about Crohn's disease types; the awareness about Crohn's disease types increased significantly as the information retrieval from the Internet increased. Conclusion: The medical history data of the patients and their families play an important role in the pathogenesis of inflammatory bowel diseases. In contrast to the literature, the findings of the present study data showed that most of our patients did not have a family history of inflammatory bowel diseases, any other disease, or appendectomy. In accordance with the literature, our data showed that the patients were smokers and consumed monotype unbalanced foods before the diagnosis of inflammatory bowel diseases was established. Inflammatory bowel diseases was also diagnosed in patients with low levels of education.

Keywords: Inflammatory bowel disease, epidemiological characteristics, disease awareness, ulcerative colitis, Crohn's disease

Özgürsoy Uran BN, Yüksel Sarıtaş E, Avdal Ünsal E, et al. Epidemiological characteristics and awareness of inflammatory bowel diseases: a cross-sectional study in Izmir. The Turkish Journal of Academic Gastroenterology 2019;18:112-119. DOI: 10.17941/agd.532735

Geliş Tarihi: 28.02.2019 • Kabul Tarihi: 09.12.2019

*14 - 18 Ekim 2015 tarihleri arasında 17. Ulusal lç Hastalıkları Kongresi'nde sözlü bildiri olarak sunulmuștur. 


\section{GíRiș}

Ülseratif kolit (ÜK) ve Crohn hastalığı (CH) olarak bilinen inflamatuvar barsak hastalıkları (iBH); ödem, ülserasyon, kanama, derin sIVı ve elektrolit kayıplarına neden olarak gastrointestinal sistemin herhangi bir kısmını etkileyebilen, yineleme ve iyileşme dönemleriyle karakterize yaşam boyu süren kronik hastalıklardır (1-6). Etiyolojilerinde birden fazla faktörün rol oynadığı düşünülmektedir. İB'nın demografik ve sosyoekonomik özellikler ile etiyolojik ilişkisi araştırımasına karşın, hastalığın patogenezi hala tam olarak aydınlatılabilmiş değildir. Çevresel etkenlerin, yeme alışkanlıklarının hastalığın ortaya çıkışında ve relapslarda rol oynadığı düşünülmektedir. IBH olgularının sadece \%22'sinde aile hikayesi olması, tek yumurta ikizlerinde yapılan çalışmalarda CH ve ÜK'nın diğer kardeşte sırasıyla $\% 27$ ve \%15 oranında görülmesi çevresel etkenlerin etiyolojideki önemli rolünü ortaya koymaktadır (7-10).

İsviçre'de sıklıkla erken yetişkinlik döneminin başlarında görülmekle beraber insidansı 100.000 bireyde $6(\mathrm{CH})$ ve 15 (ÜK) olarak; prevalansı da 100.000 bireyde $150(\mathrm{CH})$ ve 300 (ÜK) olarak saptanmıştır (11). Amerika'da, 1-1.3 milyon insanın IBH olduğu tahmin edilmektedir $(7,12)$. Ülkemizde Bolu'da yapılan bir çalışmada; İBH genel prevalansının ÜK için 31.83/105, CH için 12.53/105 olduğu saptanmıştır (13). IBH, ikinci veya üçüncü dekadda sık görülmekle birlikte, 15-30 yaş aralığında pik yapar, ancak her yaşta görülebilir. ÜK insidansı erkeklerde, $\mathrm{CH}$ insidansı kadınlarda daha fazladır. ÜK ve $\mathrm{CH}$ benzer karakteristik özelliklere sahiptir; her ikisi de iyileşme ve ataklarla seyretmektedir $(5,7,12,13)$. Can ve arkadaşlarının çalışmasında; ÜK için prevalansın en yüksek olduğu yaş aralığı (35-44 yıl), $\mathrm{CH}^{\prime}$ da (25-34 yıl); ÜK ve CH'da kadınlarda prevalansın en yüksek olduğu yaş aralığı değişmezken, erkeklerde prevalans en yüksek 45 - 54 yaş olarak belirlenmiştir (14).

Türkiye, gelişmekte olan bir ülke olarak doğuyla batı arasında geçiş konumundadır. Hastalık insidansı Batı toplumları kadar yüksek olmamakla birlikte, Doğu'daki kadar düşük değildir. Epidemiyolojik gözlemler, bu hastalıklara ait gerçek nedensel faktörleri tanımlamada yararlı olabilir. Son ylllarda Türkiye'de IBH'nin epidemiyolojik verilerine ilişkin yapılan çalışmalar bulunsa da (13-17); farkındalık durumlarını değerlendiren herhangi bir çalışmaya rastlanmamışır. Bu çalışmada; İzmir ilinde bir grup IBH olgusunun, sosyodemografik ve epidemiyolojik verilerini değerlendirerek hastalık öykülerini ve hastalığa ilişkin farkındalıklarını belirlemek amaçlanmıştır.

\section{GEREÇ ve YÖNTEM}

Tanımlayıcı ve kesitsel olarak planlanan bu çalışma İzmir'de bir eğitim ve araştırma hastanesi gastroenteroloji polikliniğine başvuran 104 IBH olgusu ile Temmuz-Ekim 2015 tarihleri arasında yürütülmüştür. Çalışmaya; hastanenin gastroenteroloji polikliniğine başvuran, Türkçe iletişim kurulabilen, IBH tanısı almış olan (yeni tanı alanlar ve takip hastaları) ve çalışmaya katılmayı kabul eden 18 yaş ve üzeri İBH olguları dâhil edilmiştir.

Çalışma verileri; literatür taraması doğrultusunda araştırmacılar tarafından oluşturulan ve $\mathrm{IBH}$ olan bireylerin sosyodemografik ve hastalık özelliklerine ilişkin sorulardan oluşan bir anket formu aracıı̆ı̆ı ile toplanmıştır. Otuz sorudan oluşan "iBH Tarama ve Farkındalık Anketi"nde hastanın yaşı, cinsiyeti, mesleği ve eğitim durumu gibi sosyodemografik soruların yanı sıra sigara içme durumu, evde birlikte yaşadığı kişi sayısı, hangi İBH türünün olduğu ve bu tanıyı ne zaman aldığı, hastalığının tutulum yeri, doğum tipi, anne sütü içme durumu gibi hastalık özelliklerine ilişkin sorular yer almıştır. Ayrıca ailesinde IBH olup olmadığı, apandisit ameliyatı geçirip geçirmediği, tanı almadan önce ağır bir barsak enfeksiyonu geçirip geçirmediği ve bu nedenle antibiyotik kullanıp kullanmadığı, İBH tanısı almadan önce nasıl beslendiği, hangi ilaçları kullandığını bilme durumu gibi hastalığa ilişkin epidemiyolojik ve farkındalığı ile ilişkili sorular da sorulmuştur (13-24).

Araştırmadan elde edilen verilerin analizi SPSS 16.0 istatistik paket programında gerçekleştirilmiştir. Çalışmada sınıflayıcı değişkenler için frekans ve yüzdeler; sürekli değişkenler için ortalama, standart sapma ve median; oranların karşılaştırmalarında ki-kare testleri kullanılmıştır. p değeri .05'in altında olan değerler istatistiksel olarak anlamlı kabul edilmiştir.

\section{Çalışmanın Etik Yönü}

Çalş̧ma için etik kurul izni ve çalışmanın yürütüleceği kurumdan izin alınmıştır. Ayrıca çalışma kapsamına alınan bireylerden "Bilgilendirilmiş Olur" alınmış ve veriler araştırmacılar tarafından yüz yüze görüşme yöntemi kullanılarak 10 dakikalık süre içinde toplanmıştır.

\section{BULGULAR}

\section{Hastaların Hastalık Özelliklerine İlişkin Veriler}

Hastaların demografik özelliklerine ilişkin veriler Tablo 1 'de gösterilmiş olup; popülasyonun yaş ortalaması 42.5 $\pm 13.9, \% 56.7$ 'si erkek ve \%75'i evlidir. Hastaların $\% 54.8$ 'i ortaokul ve üzeri eğitim düzeyine sahip iken, $\% 60.6$ 'sı çalışmadığını ya da emekli olduğunu, \%60'tan fazlası gelirinin 2000 TL'nin altında olduğunu belirtmiştir. Hastaların \%38.5'i sigarayı bırakmış, ancak \%19.2'si hala içmeye devam etmektedir.

Hastalığa ilişkin özellikler (Tablo 2) incelendiğinde ise; hastaların \%95.2'si tıbbi tanısını bilmekte ve \%60.6'sı ÜK 
olduğunu ifade etmektedir. CH olanların \%56.8'i CH tipini bilmektedir. İBH olan hastaların \%57.8'i ise hastalığın tutulum yerini; \%74.0'ı kullandıkları ilaçları bilmektedir. Çalışma grubundaki hastaların ortalama hastalık süresi $70.41 \pm 64.30$ aydır. Hastaların \%92.2'sinde soy geçmişlerinde IBH öyküsü bulunmamaktadır. Hastaların büyük çoğunluğunun normal doğum (\%94.2) ile dünyaya geldiği ve anne sütü içtikleri (\%95.2); anne sütü içme ortalamasının $10.95 \pm 12.28$ ay olduğu saptanmıştır. Hastaların tanı almadan önceki beslenme durumları sorgulandığında ise hastaların yarısının hızlı atıştırmalıklarla veya tek yönlü olarak dengesiz bir beslenme planı uyguladığı görülmüştür. Ayrıca hastaların \%58.7'i İBH dışında herhangi bir hastalığının olmadığını ve \%89.4'ü apendektomi öyküsü bulunmadığını, \%72.1'i barsak enfeksiyonu öyküsü bulunmadığını belirtmiştir (Tablo 2).

\section{Hastaların Farkındalık Durumlarına İlişkin Veriler}

Hastaların farkındalık durumları için $\mathrm{CH}$ tipini bilme durumları ile demografik özellikleri arasındaki ilişki Tablo 3'te gösterilmiş; $\mathrm{CH}$ tipini bilme durumu ile cinsiyet arasında anlamlı bir ilişki saptanmış ve erkeklerin kadınlardan daha fazla oranla $\mathrm{CH}$ tipini bildikleri görülmüştür $(p<.05)$. Öğrenim durumları "ilkokul ve altı" ile "ortaokul ve üstü" şeklinde iki gruba ayrılmış ve $\mathrm{CH}$ tipini bilme durumları değerlendirilmiştir. $\mathrm{CH}$ tipini bilme durumları ile hastaların öğrenim durumları arasındaki ilişkinin anlamlı olduğu $(p<.05)$, ortaokul ve üstü öğrenime sahip bireylerin hastalık tipini daha fazla oranla bildiği saptanmıştır. İnternetten bilgi alımı ile $\mathrm{CH}$ tipini bilme durumları arasında da anlamlı bir ilişki olduğu $(p<.05)$, internetten bilgi alımı arttıkça CH tipini bilme durumlarının da anlamlı olarak arttığı görülmüştür.

\section{Tablo 1. Hastaların demografik özellikleri}

\section{Demografik Özellikler}

\section{Yaş ortalaması (OrtıSS)}

Yaş ( $n, \%)$

$<35$ yaş

35-50 yaş arası

$>50$ yaş

Cinsiyet (n, \%)

Erkek

Kadın

\section{Öğrenim durumu ( $n, \%)$}

Illkokul ve altı

Ortaokul - Lise

Yükseköğrenim

Medeni durum ( $n$, \%)

Bekâr

Evli

Eşinden ayrı/Eşi ölmüş

Meslek ( $n, \%)$

Çalışmıyor - Emekli

Çalışıyor

Hane toplam geliri ( $n, \%)$

Belirsiz

$<2000 \mathrm{TL}$

$>2000 \mathrm{TL}$

Sigara kullanımı ( $n, \%)$

Kullanmıyor

Bırakmış

Hala kullanıyor

Sigara kullanım ortalaması (paket/ay) n

$42.5 \pm 13.9$

33

42

29

59

56.7

45

43.3

47

45.2

40

38.5

17

16.3

21

20.2

78

75.0

5

4.8

63

60.6

41

39.4

10

9.6

64

61.6

30

28.8

44

42.3

40

38.5

20

19.2

$20.93 \pm 17.93$

(min 2-mak 90)

Ort: Ortalama. SS: Standart sapma. 
Tablo 2. ïBH olan hastaların hastalıklarına ilişkin özelliklerin dağılımı

\begin{tabular}{|c|c|c|c|c|c|}
\hline Hastalık Özellikleri & $\mathbf{n}$ & $\%$ & Hastalık Özellikleri & $\mathbf{n}$ & $\%$ \\
\hline \multicolumn{3}{|l|}{ Tanısı } & \multicolumn{3}{|l|}{ Doğum tipi } \\
\hline Bilmiyor & 5 & 4.8 & Normal & 98 & 94.2 \\
\hline ÜK & 63 & 60.6 & Sezaryen & 6 & 5.8 \\
\hline $\mathrm{CH}$ & 36 & 34.6 & \multicolumn{3}{|l|}{ Ek Hastalık } \\
\hline \multicolumn{3}{|l|}{ CH tipi } & Yok & 61 & 58.7 \\
\hline Bilmiyor & 15 & 43.2 & Var & 43 & 41.3 \\
\hline Biliyor & 21 & 56.8 & \multicolumn{3}{|l|}{ Apendektomi } \\
\hline \multirow[t]{2}{*}{ Hastalık süresi (ay) } & \multicolumn{2}{|c|}{$70.41 \pm 64.30$} & \multirow{2}{*}{$\begin{array}{l}\text { Yok } \\
\text { Var }\end{array}$} & 93 & 89.4 \\
\hline & $(\min : 2$ & $\mathrm{ks}: 360)$ & & 11 & 10.6 \\
\hline \multicolumn{3}{|l|}{ Tutulum yeri } & \multicolumn{3}{|l|}{ Barsak enfeksiyonu } \\
\hline Bilmiyor & 45 & 42.2 & Hayır & 75 & 72.1 \\
\hline Biliyor & 59 & 57.8 & Evet & 29 & 27.9 \\
\hline \multicolumn{3}{|l|}{ Kullandığı ilaçlar } & \multicolumn{3}{|l|}{ Antibiyotik kullanımı } \\
\hline Bilmiyor \& Kısmen biliyor & 27 & 26.0 & Hayır & 85 & 81.8 \\
\hline Biliyor & 77 & 74.0 & Evet & 19 & 18.2 \\
\hline \multicolumn{3}{|l|}{ Ailede İBH } & \multicolumn{3}{|l|}{ Tanıdan önce beslenme tipi } \\
\hline Yok & 96 & 92.2 & Hızlı atıştırmalıklar & 10 & 9.8 \\
\hline Var & 8 & 7.8 & Sebze meyve ağırlıklı & 15 & 13.7 \\
\hline \multicolumn{3}{|l|}{ Anne sütü içme durumu } & Et ağırlıklı & 17 & 16.7 \\
\hline İçen (min: 2 - maks: 48 ay) & 99 & 95.2 & Dengeli beslenme & 52 & 50.0 \\
\hline |̧̇meyen & 5 & 4.8 & \multirow[t]{2}{*}{ Dengesiz beslenme } & \multirow[t]{2}{*}{10} & \multirow[t]{2}{*}{9.8} \\
\hline Anne sütü içme ort. (ay) & \multicolumn{2}{|c|}{$10.95 \pm 12.28$} & & & \\
\hline
\end{tabular}

Çalışma kapsamına alınan hastaların kullandıkları ilaçları bilme durumları ile öğrenim durumları arasında anlamlı bir ilişki olduğu, ortaokul ve üstü öğrenime sahip hastalarda daha fazla oranla kullandıkları ilaçları bildikleri belirlenmiştir. Kullandıkları ilaçları bilme durumları ile hane toplam geliri arasındaki ilişki incelendiğinde ise; 2000 TL'nin altında olan hastaların kullandıkları ilaçları daha fazla oranla bildikleri görülmüş ve bunun da anlamlı olduğu saptanmıştır (Tablo 4).

\section{TARTISSMA}

\section{Hastaların Hastalık Özelliklerinin Değerlendirilmesi}

Inflamatuvar barsak hastalıklarının patogenezinde sigara, enfeksiyonlar, farmakolojik ajanlar, genetik faktörler, stres, beslenme alışkanlıkları gibi birçok etkenin rol oynadığı bilinmektedir. Yapılan bu çalışmada İzmir ili örneğinde İBH patogenezinde rol oynadığı düşünülen bazı etkenler ve hastalıkları ile ilgili olarak bireylerin farkındalık durumları kesitsel olarak incelenmiştir. Literatürde kadın ve erkekler arasında sıklık bakımından bir fark olmadığı, hastalığın en sık 15-25 yaş ve 55-65 yaş arasında görüldüğü, sıklıkla 2. ve 3. dekadda, daha sonra da 6. dekadda pik yaptığı belirtilmiştir $(16,25-29)$. Örneklem kapsamına aldığımız bireylerin yaş ortalaması, literatürde belirtilenden farklı olarak 4. dekadda yer almaktadır. Eğitim düzeyi yüksek olan gruplarda İBH'nin daha fazla görüldüğünü belirten çalışmaların $(17,30)$ aksine, eğitim düzeyi düşük olan hastalarda da IBH'nin görüldüğü ifade edilmektedir $(29,32,33)$. İzmir ili örneğini ele aldığımız bu kesitsel çalışmada da hastaların eğitim düzeyi yükseldikçe İBH görülme oranının azaldığı görülmüştür. Yapılan çalışmalarda hastaların genelde evli olduğu bizim çalışmamızla uyumludur. Ancak literatürde belirtilenin aksine $(17,31,32,34)$ hastalarımızın genç yaşta olmalarına rağmen aktif çalışma hayatında olmadıkları saptanmıştır.

Beslenme, genç yaş grubunda olma, sigara alışkanlıkları, hormonal ve ilaç kullanım durumları hastalığı etkileyen faktörler olarak görülmektedir $(13,17,35)$. IBH etiyopatogenezinde önemli rolü olduğu düşünülen sigara içmenin; özellikle CH olgularında hastalığın şiddetini, hastalık tekrarlama sıklığını, tedaviye yanıı daha kötü olarak etkilediği, cerrahi müdahale gereksinimini arttırdığı bilinmek- 
Tablo 3. Crohn hastalığı tipini bilme durumu ile demografik özellikler arasındaki ilişsi

\begin{tabular}{|c|c|c|c|c|c|}
\hline \multirow{3}{*}{ Demografik Özellikler } & \multicolumn{4}{|c|}{ CH Tipi } & \multirow{3}{*}{ p } \\
\hline & \multicolumn{2}{|c|}{ Bilmiyor } & \multicolumn{2}{|c|}{ Biliyor } & \\
\hline & n & $\%$ & $n$ & $\%$ & \\
\hline \multicolumn{6}{|l|}{ Yaş } \\
\hline$<35$ yaş & 5 & 31.3 & 8 & 38.1 & \multirow{3}{*}{$>0.999$} \\
\hline $35-50$ yaş arası & 7 & 49.9 & 10 & 47.6 & \\
\hline > 50 yaş & 3 & 18.8 & 3 & 14.3 & \\
\hline \multicolumn{6}{|l|}{ Cinsiyet } \\
\hline Erkek & 5 & 33.3 & 15 & 71.4 & \multirow{2}{*}{$0.015^{*}$} \\
\hline Kadın & 10 & 66.7 & 6 & 28.6 & \\
\hline \multicolumn{6}{|l|}{ Medeni durum } \\
\hline Bekâr & 3 & 20.0 & 6 & 28.6 & \multirow{3}{*}{$>0.999$} \\
\hline Evli & 10 & 66.7 & 13 & 61.9 & \\
\hline Eşinden ayrı/Eşi ölmüş & 2 & 13.3 & 2 & 9.5 & \\
\hline \multicolumn{6}{|l|}{ Öğrenim durumu } \\
\hline İlkokul ve altı & 9 & 60.0 & 5 & 23.8 & \multirow{2}{*}{$0.044^{*}$} \\
\hline Ortaokul ve üstü & 6 & 40.0 & 16 & 76.2 & \\
\hline \multicolumn{6}{|l|}{ Meslek } \\
\hline Çalışmıyor-Emekli & 10 & 66.7 & 9 & 42.9 & \multirow{2}{*}{0.231} \\
\hline Çalışıyor & 5 & 33.3 & 12 & 57.1 & \\
\hline \multicolumn{6}{|l|}{ Hane toplam geliri } \\
\hline Belirsiz & 2 & 13.3 & 2 & 9.5 & \multirow{3}{*}{0.224} \\
\hline$<2000 \mathrm{TL}$ & 10 & 66.7 & 9 & 42.9 & \\
\hline$\geq 2000 \mathrm{TL}$ & 3 & 20.0 & 10 & 47.6 & \\
\hline \multicolumn{6}{|l|}{ Sigara } \\
\hline Kullanmıyor & 9 & 60.0 & 5 & 23.8 & \multirow{3}{*}{0.055} \\
\hline Bırakmış & 4 & 26.7 & 9 & 42.9 & \\
\hline Kullanıyor & 2 & 13.3 & 7 & 33.3 & \\
\hline \multicolumn{6}{|l|}{ İnternetten bilgi alımı } \\
\hline Hayır & 13 & 86.7 & 10 & 47.6 & \multirow{2}{*}{$0.012^{*}$} \\
\hline Evet & 2 & 13.3 & 11 & 52.4 & \\
\hline
\end{tabular}

* $p<0.05$ düzeyinde anlamlıdır. $\mathrm{CH}$ : Crohn hastalığı.

tedir. Sigaraya devam edilmesi hastalık sürecini uzatmaktadır. CH olgularında intestinal kanalda vaskülit benzeri olaylar sigara ile tetiklenmekte ve iskemik sonuçlar ortaya çıkmaktadır $(27,28)$. Yapılan çalışmalarda sigara kullanmayan hastaların da İBH tanısı alabildiği, sigara içenlerin tanı aldıktan sonra da sigara içmeye devam ettiği saptanmışıı $(25,26,36,37)$. Bizim çalışmamızda hastalık tanısı aldıktan sonra sigarayı bırakan hastalar olmasına karşın, sigara içmeye devam eden olguların hiç de azımsanmayacak düzeyde olduğu söylenebilir.

Yapılan genetik çalışmalar, İBH hastalarının dörtte birinde ailesinde bu hastalığa sahip birey(ler)in olduğunu, birinci dereceden akrabalarda İB görülme oranının \%15 olduğunu ortaya koymaktadır $(13,27,28,35,36)$. Genetik faktörlerin hastalık etiyolojisinde rol oynadığı belirtilse de küçük bir olgu serisini incelediğimiz bu çalısmada aile öyküsünde İBH olmayan hastaların olduğu saptansa da, bu veri doğrultusunda genetik açıdan bir genelleme yapılması mümkün olmamaktadır. Çalışma kapsamında değerlendirdiğimiz olgu serisinde ek hastalı̆̆ı olanların Demirbulat'ın çalışmasındaki (38) gibi azımsanmayacak bir düzeyde olduğu görülmüştür. Ayrıca bizim çalışmamızda büyük bir çoğunlukta apendektomi öyküsünün olmadığı görülmesine karşın IBH'nin yaygın çevresel faktörlerinden birinin geçmiş apendektomi öyküsü olduğu saptanmıştır $(16,28,29)$. 
Tablo 4. Kullanılan ilacı bilme durumu ile demografik özellikler arasındaki iliş̧i

\begin{tabular}{|c|c|c|c|c|c|}
\hline \multirow{3}{*}{ Demografik Özellikler } & \multicolumn{4}{|c|}{ Kullandığı İlaçlar } & \multirow{3}{*}{$\mathbf{p}$} \\
\hline & \multicolumn{2}{|c|}{ Bilmiyor \& Kısmen Biliyor } & \multicolumn{2}{|c|}{ Biliyor } & \\
\hline & $\mathbf{n}$ & $\%$ & $\mathbf{n}$ & $\%$ & \\
\hline \multicolumn{6}{|l|}{ Yaş } \\
\hline$<35$ yaş & 5 & 18.6 & 28 & 36.4 & \multirow{3}{*}{0.161} \\
\hline 35-50 yaş arası & 11 & 40.7 & 31 & 40.3 & \\
\hline$>50$ yaş & 11 & 40.7 & 18 & 23.4 & \\
\hline \multicolumn{6}{|l|}{ Cinsiyet } \\
\hline Erkek & 16 & 59.3 & 43 & 55.8 & \multirow{2}{*}{0.438} \\
\hline Kadın & 11 & 40.7 & 34 & 44.2 & \\
\hline \multicolumn{6}{|l|}{ Medeni durum } \\
\hline Bekar & 4 & 14.8 & 17 & 22.1 & \multirow{3}{*}{0.805} \\
\hline Evli & 21 & 77.8 & 57 & 74.0 & \\
\hline Eşinden ayrı/Eşi ölmüş & 2 & 7.4 & 3 & 3.9 & \\
\hline \multicolumn{6}{|l|}{ Öğrenim durumu } \\
\hline İlkokul ve altı & 17 & 63.0 & 30 & 39.0 & \multirow{2}{*}{$0.048 *$} \\
\hline Ortaokul ve üstü & 10 & 37.0 & 47 & 61.0 & \\
\hline \multicolumn{6}{|l|}{ Meslek } \\
\hline Çalışmıyor-Emekli & 19 & 70.4 & 44 & 57.1 & \multirow{2}{*}{0.493} \\
\hline Çalışıyor & 8 & 29.6 & 33 & 42.9 & \\
\hline \multicolumn{6}{|l|}{ Hane toplam geliri } \\
\hline Belirsiz & 9 & 33.3 & 3 & 3.9 & \multirow{3}{*}{$0.001 *$} \\
\hline$<2000 \mathrm{TL}$ & 13 & 48.1 & 48 & 62.3 & \\
\hline$\geq 2000 \mathrm{TL}$ & 5 & 18.6 & 26 & 33.8 & \\
\hline \multicolumn{6}{|l|}{ Sigara } \\
\hline Kullanmıyor & 9 & 33.3 & 35 & 45.5 & \multirow{3}{*}{0.369} \\
\hline Bırakmış & 12 & 44.4 & 28 & 36.4 & \\
\hline Kullanıyor & 6 & 22.3 & 14 & 18.2 & \\
\hline \multicolumn{6}{|l|}{ İnternetten bilgi alımı } \\
\hline Hayır & 19 & 70.4 & 51 & 66.2 & \multirow{2}{*}{0.138} \\
\hline Evet & 8 & 29.6 & 26 & 33.8 & \\
\hline
\end{tabular}

${ }^{*} \mathrm{p}<0.05$ düzeyinde anlamlıdır.

ÜK'in hemolitik ve non-hemolitik streptokoklar, Escherichia coli, Pseudomonas aeruginosa, Shigella, Staphylococcus, virüsler, parazitler (Escherichia histolityca) ve fungaller gibi birçok mikroorganizmanın neden olduğu enfeksiyonlar sonucunda ortaya çıkabildiği ifade edilse de (36), bu çalışmada hastaların çoğunluğunun daha önceden ağır bir barsak enfeksiyonu geçirmedikleri ve antibiyotik kullanmadıkları saptanmıştır.

Hastaların tanı almadan önceki beslenme şekilleri veya alışkanlıkları İBH gelişiminde önemli bir faktördür. Doğal beslenenlerde, posa - lif tüketenlerde, doğa ile iç içe yaşayan toplumlarda IBH önemli bir sorun değil iken; şehirleşmenin arttığı ve hızlı/ayaküstü atıştırmalıklarla beslenen Batı toplumlarında ve gelişmekte olan ülkelerde gün geçtikçe artan bir sorun olarak varlığını devam ettirmektedir $(13,35,36)$. Taze meyve, sebze ve lif tüketiminin, anne sütü almış olmanın İBH riskini düşürdüğü, fazla yağ alımının ÜK görülme riskini arttırdığı belirtilmiştir $(27,36)$. Çalışma kapsamına alınan hastaların yarısı düzensiz veya tek yönlü (sadece sebze - meyve veya et ağırlıklı) beslendiğini; neredeyse tamamı bebeklik dönemlerinde anne sütü aldığını (ort. 11 ay) ifade etmiştir.

\section{Hastaların Farkındalık Durumlarının Değerlendirilmesi}

Çalışma kapsamına alınan hastaların, bazı sosyodemografik özelliklerine göre hastalıkları ile ilişkili farkındalık durumları değerlendirilmiştir. Hastaların "tıbbi tanılarını", 
"hastalığın tutulum yerini" ve "kullandığı ilaçları" bilme durumları sorulduğunda; neredeyse tamamının tıbbi tanılarını bildiği, ancak bunların sadece yarısının tutulum bölgelerini bildiği ve büyük bir çoğunluğun da kullandığı ilaçları bildiği saptanmıştır. Hastaların hastalıkları ile ilgili farkındalıkları değerlendirildiğinde; tıbbi tanılarını bilseler de hastalığın tutulum gösterdiği yeri ve kullandıkları ilaçları tam olarak bilmemeleri nedeniyle bu konularda desteklenmesi ve farkındalıklarının arttıııması gerektiği düşünülmektedir.

Hastaların $\mathrm{CH}$ tipini bilme durumları ile demografik özellikleri karşılaştıııldığında ise; cinsiyet, öğrenim durumu, sigarayı bırakma durumu ve internetten bilgi alma durumu arasında anlamlı bir ilişki olduğu, erkeklerin ve eğitim durumu daha yüksek olanların hastalık tipini bildikleri saptanmıştır. Kadınların yanı sıra eğitim düzeyi ilkokul ve altında olan hastalara bire bir ve grup olarak eğitim ve danışmanlık hizmeti verilmesiyle, eğitim broşürleri, benzer hastalığı olan bireylerle buluşturma gibi çeşitli yöntem ve faaliyetlerle farkındalıklarının arttıııması gerekmektedir. Internetten bilgi alan ve almayan hastaların benzer oranlarda CH tipini bildiği, ancak büyük çoğunluğun hastalıkla ilgili bilgi/eğitim almadığı, bilgi alanların da doğru sağlık bilgisine ulaşıp ulaşmadıkları bilinmemektedir.

Hastalar bilgi eksiklikleri nedeniyle yaşam kalitelerinde düşme, buna bağlı olarak endişe ve kaygı düzeylerinde artma yaşarken; bilgi eksikliklerini gidermek için internet üzerinden farklı kaynaklardan bilgi arayışına girmektedir (31). Hastalık yönetiminde hastaların doğru sağlık bilgisine ulaşması önem taşımaktadır. Internette hastalık hakkında bilgi veren çok fazla kaynak bulunmakta, ancak bu kaynaklardaki bilgilerin güvenilirliği ve doğruluğu hala tartışımaktadır. Bu nedenle hastaların farkındalığını arttırmak konusunda atılacak önemli adımlardan biri internetteki bilgi kirliliği konusunda hastaları uyarmak ve bireyselleştirilmiş eğitimlerle farkındalıklarını arttırmaktır. Henüz yeni tanı almış IBH olan hastalarla yapılan bir çalışmada, hastaların bilgi gereksinimleri araştııılmış; asıl bilgi kaynağının doktor ve internet olduğu saptanmıştır (39). Literatürde klinik takipler ve ziyaretler sırasında, güncel uygulamalar ışığında yazıı ve görsel materyaller ile yüz yüze veya uzaktan/online olarak planlanmış bir eğitimin, hastalık yönetimine olumlu yönde katkı sağladığı ifade

\section{KAYNAKLAR}

1. Jones M, Wessinger S, Crowell MD. Coping strategies and interpersonal support in patients with irritable bowel syndrome and inflammatory bowel disease. Clin Gastroenterol Hepatol 2006;4:474-81.

2. Keefer $L$, Kiebles $J$, Taft TH. The role of self-efficacy in inflammatory bowel disease management: preliminary validation of a disease-specific measure. Inflamm Bowel Dis 2011;17:614-20. edilmiştir (40-43). Bu bağlamda hastalar kontrolsüz bir şekilde internetten bilgi almak yerine, bir sağlık profesyonelinden kendi tıbbi durumlarına özgü olarak yüz yüze veya online olarak planlanmış bir eğitim programına alınması farkındalık düzeylerini arttırmakla kalmayacak, yaşam kalitelerini ve hastalık yönetimini de destekleyeceği düşünülmektedir.

Hastaların farkındalıklarını etkileyen önemli parametrelerden biri de kullandıkları ilaçları bilme durumlarıdır. Hastaların öğrenim durumlarının ve gelir düzeylerinin artması, kullandıkları ilaçlarını bilme durumlarını da pozitif yönde etkilemiştir.

Sonuç olarak; hastanın öz ve soy geçmişindeki veriler IBH patogenezinde önemli rol oynamaktadır. Genetik faktörlerin etkisi hala tam olarak bilinmese de sigara kullanımının, enfeksiyon öyküsünün, stresin ve beslenme alışkanlıklarının etkisi çalışmalarla kanıtlanmıştır. Çalışma verilerimiz literatürün aksine hastalarımızın çoğunda ailesinde İBH öyküsü olmadığını ve herhangi başka bir hastaıık ya da apendektomi öyküsü bulunmadığını; buna karşın literatürle uyumlu olarak IBH tanısı almadan önce bireylerin sigara kullandığını, tek yönlü, dengesiz ve lif oranı düşük gıdalarla beslendiğini ortaya koymuştur. İzmir ili örneğinde hastalığın görülme yaşının 4. dekad olduğu ve hastaların aktif olarak çalışma yaşamında bulunmadıkları, eğitim seviyesi düşük olan bireylerde de İH görüldüğü sonucuna varılmıştır.

Hastaların hastalıklarının farkında olmaları, hastalı̆ın türü, seyri, tutulum yeri, alevlenme dönemleri gibi konularda bilinçli olmaları ve kendilerini izlemeleri hastalık yönetimine katkı sağlayabilir. Bilgi ve farkındalığı yüksek hastalarda, hastalık aktivitesinin azalacağı ve remisyonda olan hasta oranının artacağı düşünülmektedir. Henüz ülkemizde kapsamlı IBH verileri bulunmamaktadır. Benzeri epidemiyolojik taramaların daha büyük popülasyonlarla yapılması ile ülkemize özgü bir "iBH haritası" çıkarılabilir ve bu alanda daha sağlıkı veri kayıtları oluşturulabilir.

Yapılan literatür taramasında ülkemizde İBH hastalarının hastalıkları ile ilgili farkındalık durumlarını değerlendiren bir çalışmaya rastlanmamıştır. Bu nedenle çalışmamızın gelecekte yapılması planlanan çalışmalara ışık tutacağı düşünülmektedir. 
5. Pullen RL, Julian MK. Caring for a patient with inflammatory bowel disease. Nursing Made Incredibly Easy. Lippincott Williams and Wilkins 2012;10:36-45.

6. Rejler M, Spangeus A, Tholstrup J, Andersson-Gäre B. Improved population-based care: Implementing patient- and demand-directed care for inflammatory bowel disease and evaluating the redesign with a population-based registry. Qual Manag Health Care 2007;16:38-50.

7. Russel MG. Changes in the incidence of inflammatory bowel disease: what does it mean? Eur J Intern Med 2000;11:191-6.

8. Lakatos L, Kiss LS, David G, et al. Incidence, disease phenotype at diagnosis, and early disease course in inflammatory bowel diseases in Western Hungary, 2002-2006. Inflamm Bowel Dis 2011;17:2558-65

9. Thia KT, Loftus EV Jr, Sandborn WJ, Yang SK. An Update on The epidemiology of inflammatory bowel disease in Asia. Am J Gastroenterol 2008;103:3167-82.

10. Halfvarson J. Genetics in twins with crohn's disease: less pronounced than previously believed? Inflamm Bowel Dis 2011;17:612.

11. Blomqvist P, Ekbom A. IBD: Health care and costs in Sweden 1994. Scand J Gastroenterol 1997;32:1134-9.

12. .Epidemiology of IBD. http://www.cdc.gov/ibd/ibd-epidemiology. htm Erişim T: 12.02.2019.

13. Karlinger K, Györke T, Makö E, Mester A, Tarján Z. The epidemiyolody and the pathogenesis of inflammatory bowel disease. Eur J Radiol 2000;35:154-67.

14. Can G, Poşul E, Yılmaz B, et al. The rates of incidence and prevalence of inflammatory bowel diseases in Bolu/Düzce Region: Retrospective cohort study between 2004-2013. Abant Med J 2015;4:210-20

15. Özin Y, Kılıç MZ, Nadir I, et al. Clinical features of ulcerative colitis and Crohn's disease in Turkey. J Gastrointestin Liver Dis 2009;18:157-62.

16. Tözün N, Atug O, Imeryuz N, et al; Members of The Turkish IBD Study Group. Clinical characteristics of inflammatory bowel disease in Turkey: A multicenter epidemiologic survey. J Clin Gastroenterol 2009;43:51-7.

17. Tezel A, Dökmeci G, Eskiocak M, Umit H, Soylu AR. Epidemiological features of ulcerative colitis in Trakya, Turkey. J Int Med Res 2003;31:141-8.

18. Ünal HÜ. Crohn Hastalığında Tedaviye Güncel Bakış. Güncel Gastroenteroloji 2012;16:11-25.

19. Nordin K, Pahlman L, Larsson K, Sundberg-Hjelm M, Lööf L. Healthrelated quality of life and psychological distress in a populationbased sample of Swedish patients with in inflammatory bowel disease. Scand J Gastroenterol 2002;37:450-7.

20. Lichtenstein GR, Hanauer SB, Sandborn WJ; Practice Parameters Committee of American College of Gastroenterology. Management of Crohn's disease in adults. Am J Gastroenterol 2009;104:465-83.

21. Peyrin-Biroulet L, Loftus EV Jr, Colombel JF, Sandborn WJ. Long term complications, extraintestinal manifestations, and mortality in adult crohn's disease in population-based cohorts. Inflamm Bowel Dis 2011;17:471-8.

22. Jorgensen LGM, Fredholm L, Petersen PH, et al. How accurate are clinical activitiy indices for scoring of disease activity in IBD? Clin Chem Lab Med 2005;43:403-11.

23. Kovacs Z, Kovacs F. Depressive and anxiety symptoms, dysfunctional attitudes, and social aspects in irritable bowel syndrome and inflammatory bowel disease. Int J Psychiatry Med 2007;37:245-55.

24. Fuller-Thomson E, Sulman J. Depression and inflammatory bowel disease: Findings from two nationally representative Canadian surveys. Inflamm Bowel Dis 2006;12:697-707.
25. Ricanek P, Brackmann S, Perminow G, et al; IBSEN II Study Group. Evaluation of disease activicty in IBD at the time of diagnosis by clinical, biochemical, and fecal markers. Scand J Gastroenterol 2011:46:1081-91.

26. Carter MJ, Lobo AJ, Travis SPL; IBD Section, British Society of Gastroenterology. Guidelines for the management of inflammatory bowel disease in adults. Gut 2004;53 (Suppl 5):V1-V16.

27. Mercimek K. Trakya Bölgesinde inflamatuvar barsak hastalıklarının epidemiyolojik özellikleri [Uzmanlık Tezi]. Edirne: Trakya Üniversitesi Tıp Fakültesi; 2010.

28. Oktay E. Beşinci Bölüm: Inflamatuvar Barsak Hastalıkları: Etyopatogenez, Semptomatoloji, Tanı Ve Komplikasyonlar. Edt: Prof. Dr. Ertuğrul Göksoy. Prof. Dr. Hülya Uzunismail. Gastrointestinal Sistem Hastalıkları. İ.Ü.Cerrahpaşa Tıp Fakültesi Sürekli Tıp Eğitimi Sempozyum Dizisi Yayın No: 23. 2001:199-206.

29. Keeton RL, Mikocka-Walus A, Andrews JM. Concerns and worries in people living with IBD: A mixed methods study. J Psychosom Res 2015;78:573-8.

30. Diaz JA, Griffith RA, Ng JJ, et al. Patients' use of the internet for medical information. J Gen Intern Med 2002;17:180-5.

31. Elkjaer M, Shuhaibar M, Burish J, et al. E-health empowers patients with ulcerative colitis: A randomized controlled trial of the web-guided "constant-care" approach. Gut 2010;59:1652-61.

32. Hjortswang $H$, Jarnerot $G$, Curman $B$, et al. The influence of demographic and disease-related factors on health-related quality of life in patients with ulcerative colitis. Eur J Gastroenterol Hepatol 2003;15:1011-20.

33. van der Valk ME, Mangen MJJ, Leenders M, et al; COIN study group; Dutch Initiative on Crohn and Colitis. Risk factors of work disability in patients with inflammatory bowel disease - A Dutch nationwide web-based survey. J Crohns Colitis 2014;8:590-7.

34. McCombie A, Gearry R, Andrews J, Mulder R, Mikocka-Walus A. Does computerized cognitive behavioral therapy help people with inflammatory bowel disease? A randomized controlled trial. Inflamm Bowel Dis 2016;22:171-81.

35. Sartor RB. Mechanisms of disease: Pathogenesis of Crohn's disease and ulcerative colitis. Nat Clin Pract Gastroenterol Hepatol 2006;3:390-407

36. Özden A. Inflamatuvar bağırsak hastalığının tarihine kısa bir bakış. Güncel Gastroenteroloji. 2013;17:294-301.

37. Cosnes J, Beaugerie L, Carbonnel F, Gendre JP. Smoking cessation and the course of Crohn's disease; An intervention study. Gastroenterology 2001;120:1093-9.

38. Demirbulat A. Ülseratif kolit ve Crohn hastalarının demografik, klinik ve laboratuvar özellikleri ve bulguların hastalık aktivitesi ile korelasyonu [uzmanlık tezi]. Aydın: Adnan Menderes Üniversitesi; 2013.

39. Bernstein KI, Promislow S, Carr R, et al. Information needs and preferences of recently diagnosed patients with inflammatory bowel disease. Inflamm Bowel Dis 2011;17:590-8.

40. Johnson AJ, Singal SR. Impact of A web-based diabetes program and personal health record on diabetes quality of care. Journal of Management Care Medicine 2006;9:12-16.

41. Waters BM, Jensen L, Fedorak RN. Effects of formal education for patients with inflammatory bowel disease: A randomized controlled trial. Can J Gastroenterol 2005;19:235-44.

42. Elkjaer M. E-health: Web-guided therapy and disease self-management in ulcerative colitis. Impact on disease out-come, quality of life and compliance. Dan Med J 2012;59:B4478.

43. Pedersen N, Elkjaer M, Duricova D, et al. eHealth: Individualisation of infliximab treatment and disease course via a self-managed web-based solution in Crohn's disease. Aliment Pharmacol Ther 2012;36:840-9. 